\section{Quality Assessment of Two Commercially Available Species of Entomopathogenic Nematodes: Steinernema feltiae and Heterorhabditis indica}

\author{
Erick X. Caamano ${ }^{1}$, Raymond A. Cloyd ${ }^{2,5}$, Leellen F. Solter ${ }^{3}$, \\ and Declan J. Fallon ${ }^{4}$
}

ADDITIONAL INDEX WORDS. survival, biological control, pest management, infective juveniles, formulation

Summary. The quality of entomopathogenic nematodes (EPN) is critical to their success as biological control agents, but it is difficult to evaluate quality because standard procedures are not available. Generally, the quality of biological control agents is determined by field performance because end users may have minimal knowledge pertaining to the condition of biological control agents before application. This study assessed the variability in quality of commercially available EPN products. The authors evaluated preapplication survival of five EPN formulations, Steinernema feltiae (NemaShield, Nemasys, Gnat Not, Horticultural Scanmask), and Heterorhabditis indica (GrubStake-Hi), based on eight shipments/samples of each EPN product received during a 5-month period (July to November). The estimated total number of EPN delivered per shipment (i.e., sample) was compared with the expected quantity listed on the label, and percent live EPN was determined for each shipment. One-half of the shipments of Gnat Not (four of eight) contained $40 \%$ to $70 \%$ of the number of EPN expected based on the label ( 25 million). The remaining shipments contained consistently higher numbers, with $99 \%$ of the expected quantity of EPN received. Entomopathogenic nematode mean percent survival was highest for Nemasys $(\mathbf{9 8 \%})$ and lowest for Horticultural Scanmask (56\%). The overall mean percent survival for Gnat Not and GrubStake-Hi, both from the same supplier, was more than $85 \%$. Survival of EPN in the NemaShield product was as low as $50 \%$, but was typically between $65 \%$ and $75 \%$. NemaShield and Nemasys were the only two EPN products that provided return policy information if the product was damaged in any way. It is important for distributors and suppliers to ensure that EPN products are in quality condition before shipping to avoid performance failures and loss of customers. In addition, end users need to evaluate shipments upon receipt to determine the viability of EPN products.

$\mathrm{E}$ ntomopathogenic nematodes $(\mathrm{EPN})$ are used as biological control agents to regulate a variety of insect pests (Chyzik et al., 1996; Georgis et al., 2006; Gouge

This research was funded in part by the American Floral Endowment, United States Department of Agriculture $\mathrm{AD}-421$ project no. 6204-22000-017-04S, the University of Illinois, and Illinois Natural History Survey.

We thank Amy Dickinson for providing technical support and Kenneth E. Kemp for assistance in analyzing the data.

${ }^{1}$ University of Illinois, Department of Natural Resources and Environmental Sciences, 384 National Soybean Research Laboratory, Section of Ecological Entomology, 1101 West Peabody Drive, Urbana, IL 61801

${ }^{2}$ Kansas State University, Department of Entomology, 123 Waters Hall, Manhattan, KS 66506-4004

${ }^{3}$ Illinois Natural History Survey, 1816 South Oak Street, Champaign, IL 61820

${ }^{4}$ University of Hawaii, Department of Plant and Environmental Protection Sciences, 3190 Maile Way, Room 313B, Honolulu, HI, 96822

${ }^{5}$ Corresponding author. E-mail: rcloyd@ksu.edu. and Hague, 1995; Hara et al., 1993; Oguzoglu and Ozer, 2003). The two most commonly used and commercially available genera, Steinernema and Heterorbabditis, have a broad insect host range and can kill insect pests within $48 \mathrm{~h}$ (Burnell and Stock, 2000; Oguzoglu and Ozer, 2003). The use of EPN as biological control agents is challenging, and application techniques are still under development (Piggot and Wardlow, 2002). Effectiveness depends on the targeted host, and environmental conditions such as temperature and relative humidity (Choo et al., 1989; Hara et al., 1993; Lewis et al., 1992) as well as application technology (Gouge and Hague, 1995), because EPN are susceptible to desiccation (Ishibashi et al., 1987), temperature extremes, and ultraviolet radiation (Baur et al., 1995; Mason and Wright, 1997).

Despite logistical issues, the use of EPN has been successful in field and greenhouse environments to manage certain insect pests, including the black vine weevil [Otiorhynchus sulcatus(Coleoptera: Curculionidae)], cranberry girdler [Chrysoteuchia topiaria (Lepidoptera: Pyralidae)], mint root borer [Fumibotys fumalis (Lepidoptera: Pyralidae)], citrus weevil [Pachnaeus litus (Coleoptera: Curculionidae)], mole crickets [Scapteriscus spp. (Orthoptera: Gryllotalpidae)], billbugs [Sphenophorus spp. (Coleoptera: Curculionidae)], white grubs (Coleoptera: Scarabaeidae), fungus gnats [Bradysia spp. (Diptera: Sciaridae)] (Georgis et al., 2006; Hom, 1994), western flower thrips [Frankliniella occidentalis (Thysanoptera: Thripidae)], and serpentine leafminer [Liriomyza trifolii (Diptera: Agromyzidae)] (Hara et al., 1993; Piggot and Wardlow, 2002).

The use of EPN as biological control agents was considered impractical nearly 30 years ago (Gaugler et al., 2000). In fact, the first attempt to commercialize EPN did not occur until 1983, when BioSys, a Californiabased company, developed an efficient in vitro production method, which was later discontinued (Friedman, 1990; Gaugler, 2000). Currently, several companies within the United States produce or distribute EPN. However, Gaugler (1997) noted that quality of EPN is a concern and is essential for the success of pest management programs. Parrella and Heinz (1998) indicate that quality is the major factor that affects the adoption of biological control by end users.

Quality assessment of any biological control agent, whether it be a

\begin{tabular}{llll}
\hline $\begin{array}{l}\text { Units } \\
\begin{array}{l}\text { To convert U.S. to SI, } \\
\text { multiply by }\end{array}\end{array}$ & U.S. unit & SI unit & $\begin{array}{l}\text { To convert SI to U.S., } \\
\text { multiply by }\end{array}$ \\
\hline 29.5735 & $\mathrm{fl} \mathrm{oz}$ & $\mathrm{mL}$ & 0.0338 \\
2.54 & inch $(\mathrm{es})$ & $\mathrm{cm}$ & 0.3937 \\
25.4 & inch $(\mathrm{es})$ & $\mathrm{mm}$ & 0.0394 \\
$\left({ }^{\circ} \mathrm{F}-32\right) \div 1.8$ & ${ }^{\circ} \mathrm{F}$ & ${ }^{\circ} \mathrm{C}$ & $\left(1.8 \times{ }^{\circ} \mathrm{C}\right)+32$
\end{tabular}


parasitoid, predator, or pathogen, is important; however, no government agency regulates the quality of commercially produced natural enemies (Waddington, 1993). Evaluation of quality is, in fact, basically self-regulated (Grewal and Peters, 2005), and there are concerns regarding the lack of quality control standards (Fernandez and Nentwig, 1997; Losey and Calvin, 1995). The quality of natural enemies impacts their performance, and standards would increase the potential success rate of augmentative biological control programs (Vasquez et al., 2004). However, in numerous studies, EPN quality or viability was not evaluated before conducting experiments (Arthurs and Heinz, 2006; Buitenhuis and Shipp, 2005; Head et al., 2004; Kim et al., 2004; Premachandra et al., 2003; Susurluk, 2006; Vanninen and Koskula, 2003).

The quality of EPN is often determined by measuring viability or percentage of live, active infective juveniles (IJs) in an EPN suspension (Grewal and Peters, 2005). Gaugler et al. (2000) evaluated the viability and pathogenicity of different commercial EPN products, which were shipped to three different locations within particular shipments. However, they evaluated EPN quality from only one shipment per location. Greenhouse producers, however, typically order multiple shipments throughout the growing season, and quality may vary among batches in EPN production systems. Our study therefore focused on the preapplication survival of different commercially available EPN products received in multiple shipments throughout the summer and fall.

\section{Materials and methods}

E N T O M O P A T H O G E N I C NEMATODES: SOURCES, ORDERING, AND HANDLING. Entomopathogenic nematode strains used in this study were $S$. feltiae (Gnat Not; Integrated BioControl Systems, Greendale, IN), S. feltiae (Horticultural Scanmask; Biologic Co., Willow Hill, PA), S. feltiae (NemaShield; Bioworks, Fairport, NY), S. feltiae (Nemasys; Becker Underwood, Ames, IA), and H. indica (GrubStake-Hi; Integrated BioControl Systems). Table 1 provides specifics on the formulation of the different EPN products used in the study.

Specific dates were chosen to begin the experiments, and suppliers were contacted to deliver the EPN products on those dates. All shipments (i.e., samples) were "blind orders," as suggested by O'Neil et al., (1998) to avoid biasing the quality of the shipments (samples) from the distributor or supplier. The EPN products that arrived before the expected dates were removed from the shipping package (when present) and refrigerated at $7 \pm 2{ }^{\circ} \mathrm{C}$ until tested (1-3 d after receipt). This temperature was appropriate for EPN survival within the 3 -d period (Strauch et al., 2000; S. Hove and R. Martin, pers. comm.). The processing date as indicated in Table 2 was when we evaluated the quality of the EPN products; this is not the date on which we received all the EPN products.

AsSESSMENT OF COMMERCIALLY AVAILABLE ENTOMOPATHOGENIC NEMATODES: VIABILITY AND NUMBERS PER PACKAGE. The EPN were extracted from the packages and processed as follows. Each individual package, of 25 or 50 million EPN (Table 1), was diluted in 2500 or $5000 \mathrm{~mL}$ sterile tap water using a 5000-mL beaker. These EPN solutions were then diluted to obtain a final concentration of 100 EPN per milliliter. Ten milliliters of the suspension (1000 EPN) were pipetted into a glass Petri dish $(100 \times 15 \mathrm{~mm})$, and the numbers of live IJs and dead juveniles were counted under $20 \times$ magnification using a dissecting microscope. A plastic grid was positioned underneath each Petri dish to assist in accurately counting the numbers of EPN. Juveniles that were not actively moving when inspected visually were probed with a dissecting needle to verify that they were dead rather than resting. Dead juveniles are completely extended, in contrast to live IJs, which have a slight "J" curvature at the end of the body or are actively moving (Kaya and Stock, 1997). For each of the five commercial EPN products, $1010-\mathrm{mL}$ determinations were assessed for each shipment (sample) of each product, which represented a repeatedmeasures design. Eight different shipments of each product were evaluated over a 5-month period (July to November).

The number of live IJs and dead juveniles was recorded to obtain the proportion of live IJs per determination. To estimate the total number of juveniles delivered/shipment (sample), an average of the number of juveniles obtained from the 10 determinations (1000 EPN/determination) was calculated, multiplied by the total amount of suspension, and compared with the total number of EPN stated on the label that were included in the shipment. We used the PROC MIXED procedure (SAS version 8.2 for Windows; SAS Institute, Cary, NC) to perform a repeated-measures analysis of variance on the arcsine square root-transformed proportions. The model included EPN product as a fixed effect and shipment (sample) as a random effect, with the determinations within shipments (samples) as the repeated measures. A Fisher's protected LSD test was conducted to compare differences among the EPN products (SAS

Table 1. Commercially available entomopathogenic nematode (EPN) strains, including commercial name, scientific, company information, and formulation.

\begin{tabular}{llll}
\hline Commercial name & \multicolumn{1}{c}{ EPN } & \multicolumn{1}{c}{ Manufacturer } & Formulation \\
\hline Gnat Not & Steinernema feltiae & Integrated BioControl Systems, Inc., & 25 million IJs (sponge) \\
& & Greendale, IN & \\
GrubStake-Hi & Heterorhabdits indica & Integrated BioControl Systems, Inc. & 25 million IJs (sponge) \\
Horticultural Scanmask & S. feltiae & Biologic Co., Willow Hill, PA & 25 million IJs (sponge) \\
NemaShield & S. feltiae & Bioworks, Inc., Fairport, NY & 50 million IJs (gel) \\
Nemasys & S. feltiae & Becker Underwood, Inc., Ames, IA & 50 million IJs (gel) \\
\hline
\end{tabular}

EPN, entomopathogenic nematode; IJs, infective juveniles. 


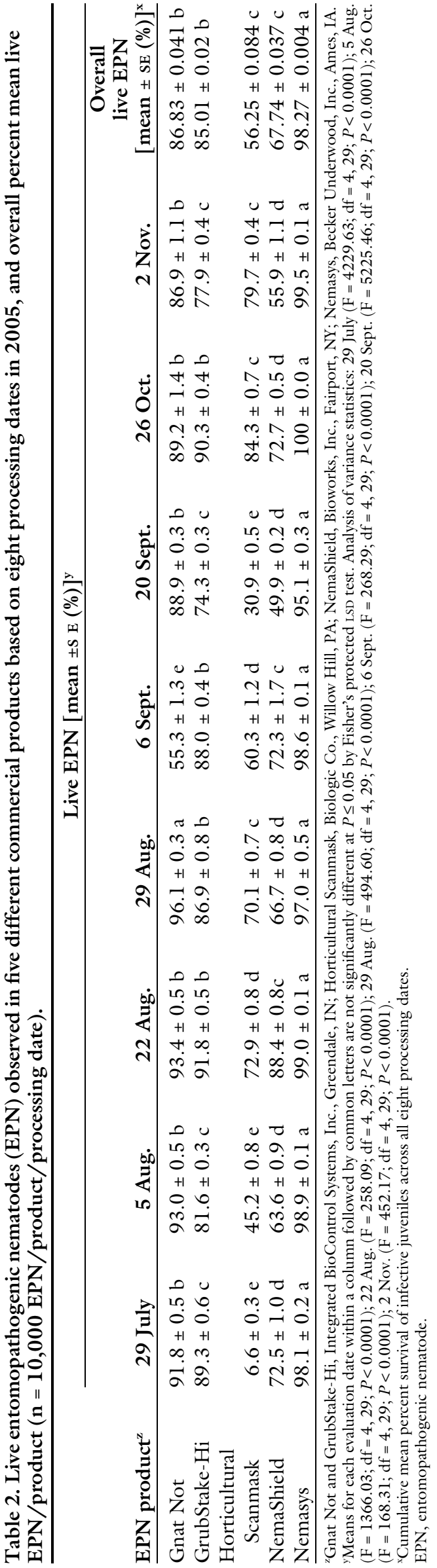

version 8.2 for Windows). All data presented are nontransformed.

Finally, we determined the estimated mean number of live IJs per product for each shipment by multiplying the mean percent of EPN received per shipment by the expected number of EPN stated on the label. This value was then multiplied by the mean percent of live IJs for each shipment date.

\section{Results}

Entomopathogenic nematode survival was significant for each processing date (Table 2) and differed significantly $(\mathrm{F}=15.06 ; \mathrm{df}=4,35$; $P<0.0001$ ) across the commercially available EPN products. Entomopathogenic nematode survival (based on percent live IJs) was highest for Nemasys, with the most consistent percent survival (95\% to $100 \%$ ) across the eight evaluation periods (Table 2 ). Mean percent IJ survival values for Gnat Not were between $87 \%$ and $97 \%$ except for one shipment, where nearly half $(45 \%)$ the EPN were dead. GrubStake-Hi mean percent IJ survival values were between $74 \%$ and $92 \%$, whereas, in most cases, mean percent IJ survival values of NemaShield were between $65 \%$ and $75 \%$. Horticultural Scanmask had the lowest mean percent IJ survival values; one shipment contained only $7 \%$ live IJs (Table 2 ).

One-half of the Gnat Not shipments (four of eight) contained lower numbers of EPN than expected: $40 \%$ to $70 \%$ of the labeled quantity (25 million EPN). Several other EPN products contained lower numbers of IJs than indicated on the label; however, the number of IJs determined for each shipment was $\geq 90 \%$ of the label quantity (e.g., 45 million as opposed to 50 million). One shipment of GrubStake-Hi contained lower numbers than labeled (92\%), as did Horticultural Scanmask (94\%) and NemaShield (96\%). All remaining shipments contained at least $99 \%$ of the number of EPN indicated on the label. The number of EPN delivered (live and dead) and estimated number of live EPN for seven shipments that provided less than $99 \%$ than expected, based on the label, is presented in Table 3.

\section{Discussion}

The quality of commercially produced EPN may vary among batches 
Table 3. Number of entomopathogenic nematodes (EPN) received (live and dead) and estimated number of live EPN for seven shipments that provided less than $99 \%$ than expected, based on the label.

\begin{tabular}{llcc}
\hline $\begin{array}{l}\text { Shipping date } \\
\text { in 2005 }\end{array}$ & EPN product & $\begin{array}{c}\text { EPN received } \\
\text { (million) }\end{array}$ & $\begin{array}{r}\text { Estimated live } \\
\text { EPN (million) }\end{array}$ \\
\hline 29 July & Gnat Not & 17.2 & 15.8 \\
22 Aug. & Gnat Not & 10.4 & 9.7 \\
20 Sept. & Gnat Not & 11.5 & 10.2 \\
2 Nov. & Gnat Not & 15.8 & 13.7 \\
29 July & GrubStake-Hi & 22.9 & 20.5 \\
29 July & Horticultural & 23.6 & 1.5 \\
& Scanmask & & \\
6 Sept. & NemaShield & 48.2 & 34.8 \\
\hline
\end{tabular}

${ }^{\mathrm{z}}$ Gnat Not and GrubStake-Hi, Integrated BioControl Systems, Inc., Greendale, IN; Horticultural Scanmask, Biologic Co., Willow Hill, PA; NemaShield, Bioworks, Inc., Fairport, NY.

EPN, entomopathogenic nematode.

of particular EPN products (Westerman and Jung, 1992) and from season to season associated with a single producer. It is important to maintain quality during all stages of production; however, additional factors such as storage temperature, relative humidity, or refrigeration may influence EPN quality before receipt by end users (Hom, 1994). Although loss of quality during storage is common (van Lenteren and Woets, 1988) the successful use of EPN is contingent on stability during shipping and storage, which may impact EPN survival and thus their effectiveness against target insect pests. In addition, confidence in the quality of a product is critical to the viability and success of using EPN as biological control agents.

In this study we found variable numbers of live IJs shipped compared with product labels and variable numbers of live IJs across shipments and products per shipment over the 5month evaluation period. Gnat Not was the most inconsistent product based on the numbers of IJs provided compared with the label. For example, two shipments (22 Aug. and 20 Sept. 2005) contained between 10 and 12 million IJs, and two shipments (29 July and 2 Nov. 2005) contained between 16 and 23 million IJs instead of the 25 million expected. In contrast, only one shipment each of GrubStake-Hi, Horticultural Scanmask, and NemaShield was received with lower numbers of IJs than that specified on the label; however, all three contained more than $90 \%$ of expected. Nemasys had the highest mean percent IJ survival (>95\%) across the eight evaluation periods
(Table 2). Mean percent IJ survival values for Gnat Not and GrubStake$\mathrm{Hi}$, both from the same supplier, were more than $85 \%$. NemaShield and Horticultural Scanmask had the lowest overall mean percent IJ survival across all eight evaluation periods, although the range among shipments was greater for Horticultural Scanmask $(6.6 \%$ to $84.3 \%)$ than NemaShield ( $49.9 \%$ to $88.4 \%$ ).

Nemasys and NemaShield were the only two commercially available EPN products that offered a return policy indicating that if cold packages had melted, the product should not be used but instead should be immediately returned to the provider for a replacement shipment. Two shipments of NemaShield (20 Sept. and 2 Nov. 2005) arrived with melted ice packages. In addition, these shipments emanated a putrid odor, possibly indicating microbial contamination, which probably affected EPN survival. These shipment dates had the lowest mean percent IJ survival values $(49.9 \%$ and $55.9 \%$ respectively) across all shipments received (Table 2). Overall, Horticultural Scanmask had the lowest and most variable quality of all the EPN products tested. It is not known whether this is the result of the processing of the EPN or issues associated with packaging, handling, or shipping conditions.

Quality control is rarely considered after natural enemies have been handled in preparation for shipment (van Lenteren, 1986). Maintaining EPN quality is essential and may be accomplished by implementing quality control programs (Georgis, 1990 ) that are designed to minimize variability in EPN viability and pathogenicity during production (Georgis, 1992). Gaugler and Georgis (1991) indicated that the production process did not affect the quality of $S$. carpocapsae based on the results obtained in greenhouse and field tests. Production of $H$. bacteriophora in liquid culture, however, results in lower EPN quality than when this species is produced in solid culture or in vivo, possibly resulting from low lipid reserves (Abu Hatab and Gaugler, 1999). Producers of EPN have made substantial progress in delivering and providing quality products (Gaugler et al., 2000). However, there are still no standards designed to define or evaluate quality of EPN products. Thus, it is critical for commercial suppliers or producers to ensure their EPN products are of the highest quality upon arrival so that end users are confident that EPN products will effectively control the designated insect pest (van Lenteren and Woets, 1988). A quality assessment should not only be based on laboratory evaluations, but on the performance of EPN in the field (O’Neil et al., 1998).

Although Gaugler et al. (2000) found potential quality issues across different commercially available EPN products when evaluating only one EPN shipment for each of several locations, with lower than expected IJ numbers (based on the label) to be the most disconcerting, there are still few published studies that have addressed quality, based on the number of live, active IJs, of commercially available products. This is the primary reason that we conducted this study. In fact, the results obtained from our research will be valuable to practitioners of biological control in terms of EPN product selection and success in controlling insect pests. Our study differed from that of Gaugler et al. (2000) in that we evaluated EPN quality over time (5-month time period) and evaluated multiple shipments per product $(\mathrm{n}=8)$.

The formulation and packaging of the different EPN products we ordered varied, which may have contributed to retention or loss of EPN quality. For example, Nemasys was delivered in sealed plastic containers $(3.5 \times 3.5$ inches $)$ in a gel matrix formulation, and NemaShield was shipped in a gel-type solution incorporated onto a moist, square piece 
$(\approx 5.5 \times 5.5$ inches $)$ of sponge contained in a plastic bag. The other three EPN products were only prepared in a moist, square piece of sponge. It is possible that the gel matrix provided a more favorable packaging environment for survival than did the sponges, especially under potentially extreme conditions encountered during shipment. Quantitative research is needed to determine which formulation and packaging is likely to result in higher EPN percent survival.

Complete contact information and explicit instructions for returning damaged products was only provided by the suppliers of Nemasys and NemaShield. This type of information would allow end users to contact the companies regarding problem shipments and to expedite receipt of new product. In general, the service that end users receive from the supplier or distributor of biological control agents such as EPN may not be sufficient (van Lenteren et al., 1980a) and, when EPN are delivered via the postal service, poor shipping conditions may result in receiving dead or injured EPN (van Lenteren et al., 1980b).

We suggest, when there are concerns regarding temperature in transit, that suppliers or distributors of EPN products consider incorporating recording devices such as data loggers in the packages of each shipment (Grewal and Peters, 2005). However, this cannot increase the cost so much that it discourages the use of EPN. The development of a rapid evaluation technique to determine the quality of EPN would allow end users to assess quickly whether the product should be applied. Moreover, end users need to ensure quality before use via proper storage after receiving any EPN product, and to check shipments to determine viability. Dead or inactive EPN in a product will reduce the number of viable units available for application and thus reduce total efficacy of the labeled product.

There are few published studies associated with quality assessment of EPN. However, as demonstrated in our study, the commercially available EPN products vary in their quality, based on survival of EPN. This is a concern because if EPN fail to perform to the end users' expectations, in all likelihood the end users will use another pest control option, including the use of insecticides, and it will be difficult to convince them to use EPN again. However, attention to the issues we have elucidated may prevent failure of EPN products and ensure that end user expectations are met, which will enhance the use of biological control as a management strategy to deal with insect pests in greenhouses.

\section{Literature cited}

Abu Hatab, M.A. and R. Gaugler. 1999. Lipids of in vivo and in vitro cultured Heterorhabditis bacteriophora. Biol. Control 15:113-118.

Arthurs, S. and K.M. Heinz. 2006. Evaluation of the nematodes Steinernema feltiae and Thripinema nicklewoodi as biological control agents of western flower thrips Frankliniella occidentalis infesting chrysanthemum. Biocontrol Sci. Technol. 16:141-155.

Baur, M.E., H.K. Kaya, and G.S. Thurston. 1995. Factors affecting entomopathogenic nematode infection of Plutella xilostella on a leaf surface. Entomol. Exp. Appl. 77:239-250.

Buitenhuis, R. and J.L. Shipp. 2005. Efficacy of entomopathogenic nematode Steinernema feltiae (Rhabditida: Steinernematidae) as influenced by Frankliniella occidentalis (Thysanoptera: Thripidae) developmental stage and host plant stage. J. Econ. Entomol. 98(5):1480-1485.

Burnell, A.M. and S.P. Stock. 2000. Heterorhabditis, Steinernema and their symbionts-lethal pathogens of insects. Nematology 2:31-42.

Choo, H.Y., H.K. Kaya, T.M. Burlando, and R. Gaugler. 1989. Entomopathogenic nematodes: Host-finding ability in the presence of plant roots. Environ. Entomol. 18:1136-1140.

Chyzik, R., I. Glazer, and M. Klein. 1996. Virulence and efficacy of different entomopathogenic nematode species against western flower thrips (Frankliniella occidentalis). Phytoparasitica 24:103-110.

Fernandez, C. and W. Nentwig. 1997. Quality control of the parasitoid Aphidius colemani (Hym., Aphidiidae) used for biological control in greenhouses. J. Appl. Entomol. 121:447-456.

Friedman, M.J. 1990. Commercial production and development, p. 157-172. In: R. Gaugler and H. Kaya (eds.). Entomopathogenic nematodes in biological control. CRC Press, Boca Raton, FL.
Gaugler, R. 1997. Alternative paradigms for biopesticides. Phytoparasitica 25:179182.

Gaugler, R. 2000. Matching nematodes to target pests. IPM Practitioner 22:1-6.

Gaugler, R. and R. Georgis. 1991. Culture method and efficacy of entomopathogenic nematodes (Rhabditida: Steinernematidae and Heterorhabditidae). Biol. Control 1:269-274.

Gaugler, R., P. Grewal, H.K. Kaya, and D. Smith-Fiola. 2000. Quality assessment of commercially produced entomopathogenic nematodes. Biol. Control 17:100-109.

Georgis, R. 1990. Formulation and application technology, p. 173-191. In: R. Gaugler and H. Kaya (eds.). Entomopathogenic nematodes. CRC Press, Boca Raton, FL.

Georgis, R. 1992. Present and future prospects for entomopathogenic nematode products. Biocontrol Sci. Technol. 2:83-99.

Georgis, R., A.M. Koppenhofer, L.A. Lacey, G. Belair, L.W. Duncan, P.S. Grewal, M. Samish, L. Tan, P. Torr, and R.W.H.M. van Tol. 2006. Successes and failures in the use of parasitic nematodes for pest control. Biol. Control 38:103-123.

Gouge, D.H. and N.G.M. Hague. 1995. Glasshouse control of fungus gnats, Bradysia paupera, on fuchsias by Steinernema feltiae. Fundam. Appl. Nematol. 18:77-80.

Grewal, P.S. and A. Peters. 2005. Formulation and quality, p. 79-90. In: P. Grewal, R.-U. Ehlers, and D. Shapiro-Ilan (eds.). Nematodes as biocontrol agents. CABI International, Wallingford, UK.

Hara, A.H., H.K. Kaya, R. Gaugler, L.M. Lebeck, and C.L. Mello. 1993. Entomopathogenic nematodes for biological control of the leafminer, Liriomyza trifolii (Dip.: Agromyzidae). Entomophaga 38:359-369.

Head, J., A.J. Lawrence, and K.F.A. Walters. 2004. Efficacy of the entomopathogenic nematode, Steinernema feltiae, against Bemisia tabaci in relation to plant species. J. Appl. Entomol. 128:543-547.

Hom, A. 1994. Current status of entomopathogenic nematodes. IPM Practitioner 16:1-12.

Ishibashi, N., S. Tojo, and H. Hatate. 1987. Desiccation survival of Steinernema feltiae str DD-136 and possible desiccation protectants for foliage application of nematodes, p. 139-144. In: N. Ishibashi (ed.). Recent advances in biological control of insect pests by entomogenous nematodes in Japan. Grant no. 59860005. Ministry of Education, Japan. 
Kaya, H.K. and S.P. Stock. 1997. Techniques in insect nematology, p. 281-322. In: L. Lacey (ed.). Manual of techniques in insect pathology. Academic Press, San Diego, CA

Kim, H.H., H.Y. Choo, H.Y. Kaya, D.W. Lee, S.M. Lee, and H.Y. Jeon. 2004. Steinernema carpocapsae (Rhabditida: Steinernematidae) as a biological control agent against fungus gnat Bradysia agrestis (Diptera: Sciaridae) in propagation houses. Biocontrol Sci. Technol. 14: $171-183$

Lewis, E.E., R. Gaugler, and R. Harrison. 1992. Entomopathogenic nematode host finding: Response to host contact cues by cruise and ambush foragers. Parasitology 105:309-315.

Losey, J.E. and D.D. Calvin. 1995. Quality assessment of four commercially available species of Trichogramma (Hymenoptera: Trichogrammatidae). J. Econ. Entomol. 88:1243-1250.

Mason, J.M. and D.J. Wright. 1997. Potential for the control of Plutella xylostella larvae with entomopathogenic nematodes. J. Invertebr. Pathol. 70:234242 .

Oguzoglu, U.I. and N. Ozer. 2003. Evaluation of the reproductive potential and competition between two entomopathogenic nematodes, Steinernema feltiae Filipjev, 1934 (Rhabditida: Steinernematidae) and Heterorhabditis bacteriophora, Poinar 1976 (Rhabditida: Heterorhabditidae). Turk. J. Biol. 27: 149-155.

O’Neil, R.J., K.L. Giles, J.J. Obrycki, D.L. Mahr, J.C. Legaspi, and K. Katovich. 1998. Evaluation of the quality of four commercially available natural enemies. Biol. Control 11:1-8.

Parrella, M.P. and K.M. Heinz. 1998. Parasitoids for control of greenhouse pests, p. 27-39. In: R. Ridgeway, M. Hoffman, M. Insoe, and C. Glenister (eds.). Mass-reared natural enemies: Application, regulation, and needs Proceedings Thomas Say Publication in Entomology. Entomological Society of America, Lanham, MD.

Piggot, S. and L. Wardlow. 2002. A fresh solution for the control of western flower thrips: Dramatic results in trials. Commercial Greenhouse Grower. Feb. 2002.

Premachandra, D.W.T.S., C. Borgemeister, O. Berndt, R.-U. Ehlers, and H.-M. Poehling. 2003. Laboratory bioassays of virulence of entomopathogenic nematodes against soil-inhabiting stages of Frankliniella occidentalis Pergande (Thysanoptera: Thripidae). Nematology 5:539-547.

Strauch, O., I. Niemann, A. Neumann, A.J. Schmidt, A. Peters, and R.-U. Ehlers. 2000. Storage and formulation of the entomopathogenic nematodes Heterorhabditis indica and $H$. bacteriophora. BioControl 45:483-500.

Susurluk, A. 2006. Effectiveness of the entomopathogenic nematodes Heterorhabditis bacteriophora and Steinernema feltiae against Tenebrio molitor (yellow mealworm) larvae in different soil types at different temperatures. Turk. J. Biol. 30:199-205.

van Lenteren, J.C. 1986. Evaluation, mass production, quality control and release entomophagous insects, p. 31-56. In: J. Franz (ed.). Biological control and health protection. Gustav Fischer, Stuttgart, Germany.

van Lenteren, J.C., P.M.J. Ramakers, and J. Woets. 1980a. Integrated control of vegetable pests in greenhouses, p. 109118. In: A. Minks and P. Gruys (eds.). Integrated control of insect pests in The Netherlands. Centre for Agricultural Publication and Documentation, Wageningen, The Netherlands.

van Lenteren, J.C., P.M.J. Ramakers, and J. Woets. 1980b. World situation of biological control in greenhouses, with special attention to factors limiting application. Mededelingen van de Faculteit Landbouwwetenschappen, Universiteit Gent 45:537-544.

van Lenteren, J.C. and J. Woets. 1988. Biological and integrated pest control in greenhouses. Annu. Rev. Entomol. 33: 239-269.

Vanninen, I. and H. Koskula. 2003. Biological control of the shore fly (Scatella tenuicosta) with steinernematid nematodes and Bacillus thuringiensis var. thuringinesis in peat and rockwool. Biocontrol Sci. Technol. 13:47-63.

Vasquez, G.M., D.B. Orr, and J.R. Baker. 2004. Quality assessment of selected commercially available whitefly and aphid biological control agents in the United States. J. Econ. Entomol. 97:781-788.

Waddington, C. 1993. Quality control in the biocontrol industry. IPM Practitioner $15: 11-13$.

Westerman, P.R. and K. Jung. 1992. Quality control of insect parasitic nematodes. Annu. Mtg. Soc. Invertebrate Pathol. 25:191. (abstr.). 